\title{
Cardiac surgery for carcinoid heart disease
}

\author{
Hiroaki Takahashi, MD, PhD \\ Yutaka Okita, MD, PhD
}

Received: 27 January 2011

(C) The Japanese Association for Thoracic Surgery 2011

\section{Introduction}

Carcinoid is a rare tumor originating from neuroendocrine cells, which are generally localized in the gastrointestinal tract. It has an annual incidence of 1.5 persons per $100000 .^{1,2}$ Usually, only carcinoid tumors that invade the liver result in pathological changes to the heart. The cardiac manifestations are caused by paraneoplastic effects of vasoactive substances such as serotonin, bradykinin, tachykinins, histamine, and prostaglandins that are released by the malignant cells, rather than by direct cardiac metastatic involvement. ${ }^{1,2}$ Carcinoid heart disease is manifested by structural changes in the right heart secondary to severe fibrotic endocardial plaques resulting from elevated blood concentrations of these vasoactive substances. Therefore, carcinoid heart disease is a rare but important cause of intrinsic tricuspid and pulmonary valve disease, leading to significant morbidity and mortality secondary to right heart failure.

Mitral or aortic valve dysfunction is less frequent and presents usually as regurgitation. Because the vasoactive substances that are produced by the tumor are metabolized in the lungs, the presence of left heart disease usually reflects the presence of a persistent foramen

This editorial refers to the article by Komoda et al. on pp. 780-785 of this issue of General Thoracic and Cardiovascular Surgery.

H. Takahashi $\cdot$ Y. Okita $(\bowtie)$

Division of Cardiovascular Surgery, Department of Surgery, Kobe University Graduate School of Medicine, 7-5-2 Kusunokicho, Chuo-ku, Kobe, Hyogo 650-0017, Japan

Tel. +81-78-382-5942; Fax +81-78-382-5959

e-mail: yokita@med.kobe-u.ac.jp ovale or, less commonly, is due to a bronchopulmonary carcinoid or poorly controlled carcinoid syndrome. ${ }^{2}$

\section{Histopathology}

A recent surgical pathology series from the Mayo Clinic described 139 valves excised from 75 patients with carcinoid heart. ${ }^{3}$ The carcinoid plaque consisted of a cellular component (myofibroblasts) and an extracellular component (collagen, myxoid matrix, and elastin). ${ }^{4}$ Other features included neovascularization, chronic inflammation, and mast cells. Severe fibrosis, with severe collagenization, primarily affected tricuspid valve plaque, whereas severe thickening of the pulmonary valves was principally caused by proliferation of myofibroblasts and deposition of myxoid matrix. Some reports indicated that the pathophysiological changes is an effect of serotonin. Gustafsson et al. demonstrated that daily injections with serotonin induce similar morphological and pathological valvular abnormalities in rats. ${ }^{5}$ Patients with carcinoid tumors without valvulopathy have lower plasma levels of serotonin and lower urinary levels of 5-hydroxyindoleacetic acid (5-HIAA), a metabolite of serotonin, than those with valvulopathy. The urinary 5-HIAA level is not only a marker for the severity of the valvular disease but also a maker for progression of valvulopathy. ${ }^{6,7}$

\section{Timing of valve surgery}

Carcinoid syndrome associated with symptomatic right heart failure has an unfavorable prognosis if only treated medically. ${ }^{8}$ Cardiac involvement is a major cause of 
morbidity and mortality, and cardiac surgery is the only definitive treatment. ${ }^{9}$ Surgery for carcinoid heart disease, once undertaken only in severely symptomatic patients, is now proposed for those who are mildly symptomatic because it is clear that waiting for the progression of heart failure increases perioperative mortality. ${ }^{10,11}$ Furthermore, the Mayo clinic experience suggested that cardiac valve replacement for symptomatic patients had a beneficial effect, causing a reduction in right ventricular size during the postoperative period. ${ }^{9}$ In their study, right ventricular function did not improve. The optimal timing of surgery in relation to the severity of valve dysfunction and symptoms has not been identified. However, on the basis of these data, cardiac surgery at the onset of either symptoms or right ventricular dysfunction may be considered. To optimize surgical outcome and reduce perioperative and postoperative complications, it is important to control the circulating vasoactive carcinoid tumor products before heart valve replacement. ${ }^{11}$ Bhattacharyya et al. noted that patients with carcinoid heart disease were referred for valve surgery if they met the following criteria: (1) stable carcinoid tumor, (2) severe valvular dysfunction, (3) symptomatic, and (4) had no other significant co-morbidities. ${ }^{12}$

Komoda et al. focused on various points from previous reports. ${ }^{13}$ They showed that postoperative prognosis could be worse when preoperative the left ventricular ejection fraction is borderline, even if it is within the normal limits. They suggested that the predictors of postoperative outcome may be not only signs of right ventricular failure, such as right ventricular volume overload and right ventricular function, but also preoperative left ventricular function in those patients, although their study consists of relative small number of patients.

\section{Cardiac valve surgery}

Surgical valve replacement rather than repair needs to be considered because of the severe retraction and fixation of the leaflets. ${ }^{14}$ As for selection of the prostheses in the tricuspid position, early reports recommended using a mechanical prosthesis based on the assumption that circulating vasoactive tumor substances may damage bioprosthetic valves. ${ }^{15}$ However, mechanical prostheses are not ideal because patients with carcinoid syndrome often have extensive liver metastases and hepatic dysfunction, and they are at high risk of bleeding due to the use of lifelong anticoagulation. Furthermore, the 3-year survival for patients with carcinoid heart disease is $31 \%$ compared with $68 \%$ for those without cardiac involvement. ${ }^{8}$ The bioprosthetic valves tend to have greater life expectancy than that of patients with carcinoid heart disease. The introduction of another therapy, such as octreotide and hepatic artery interruption, might potentially protect the bioprosthetic valve from the adverse effects of vasoactive peptides. Moreover, the potential danger of involvement of the bioprosthetic cusps in the carcinoid process may also be prevented by surgical therapy against the primary carcinoid tumor.

There is some debate regarding optimal surgical management of the pulmonary valve, such as valvectomy or valve replacement. ${ }^{11}$ However, Connolly et al. suggested that pulmonary valve replacement in addition to tricuspid valve replacement has been shown to reduce right ventricular size after surgery compared with that of patients with isolated tricuspid valve replacement, despite some patients having relatively mild pulmonary valve disease. ${ }^{9}$ In the pulmonary position, a stentless bioprosthesis is preferred because of its excellent hemodynamic characteristics and flexibility. ${ }^{4}$

\section{Conclusion}

Komoda et al. ${ }^{13}$ send a significant new message in that the timing of cardiac surgery may be important for improving patients' outcomes. Currently, it is considered preferable for patients with stable carcinoid tumor to undergo surgery early or soon after the onset of cardiac symptoms, as delay can result in worsening right ventricular failure and increase the risk of surgery. Therefore, echocardiography is mandatory in patients with carcinoid disease. In addition, the diagnosis of carcinoid syndrome should be recognized as an etiology in patients with organic tricuspid and pulmonary regurgitation without left valvular disease, although carcinoid heart disease is a rare form of valvular heart disease.

\section{References}

1. Bernheim AM, Connolly HM, Hobday TJ, Abdel MD, Pellika PA. Carcinoid heart disease. Prog Cardiovasc Dis 2007;49: 439-51.

2. Bhattacharyya S, Davar J, Dreyfus G, Caplin ME. Carcinoid heart disease. Circulation 2007;116:2860-5.

3. Simula DV, Edwards WD, Tazelaar HD, Connolly HM, Schaff HV. Surgical pathology of carcinoid heart disease: a study of 139 valves from 75 patients spanning 20 years. Mayo Clin Proc 2002;77:139-47.

4. Takahashi H, Okada K, Asano M, Matsumori M, Morimoto Y, Okita Y. Bioprosthetic pulmonary and tricuspid valve replacement in carcinoid heart disease from ovarian primary cancer. Circ J 2009;73:1554-6.

5. Gustafsson BI, Tommeras K, Nordrum I, Loennechen JP, Brunsvik A, Solligard E, et al. Long-term serotonin administration induces heart valve disease in rats. Circulation 2005;111:1517-22. 
6. Dumoulein M, Verslype C, van Cutsem E, Meuris B, Herijgers P, Flameng W, et al. Carcinoid heart disease: case and literature review. Acta Cardiol 2010;65:261-4.

7. Zuetenhorst JM, Bonfrer JM, Korse CM, Bakker R, van Tinteren H, Taal BG. Carcinoid heart disease. Cancer 2003;97:1609-15.

8. Pellika PA, Tajik AJ, Khandheria BK, Seward JB, Callahan JA, Pitot HC, et al. Carcinoid heart disease: clinical and echocardiographic spectrum in 74 patients. Circulation 1993;87: 1188-96.

9. Connolly HM, Schaff HV, Mullany CJ, Abel MD, Pellikka PA. Carcinoid heart disease: impact of pulmonary valve replacement in right ventricular function and remodeling. Circulation 2002;106(suppl):I-51-6.

10. Moller JE, Pellikka PA, Bernheim AM, Schaff HV, Rubin J, Connolly HM. Prognosis of carcinoid heart disease: analysis of 200 cases over two decades. Circulation 2005;112:3320-7.
11. Gustafsson BI, Hauso O, Drozdov I, Kidd M, Modlin IM. Carcinoid heart disease. Int J Cardiol 2008;129:318-24.

12. Bhattacharyya S, Raja SG, Toumpanakis C, Caplin ME, Dreyfus GD, Davar J. Outcomes, risks and complications of cardiac surgery for carcinoid heart disease. Eur J Cardiothorac Surg 2011;40:168-72.

13. Komoda S, Komoda T, Pavel ME, Morawietz L, Wiedenmann B, Hetzer R, et al. Cardiac surgery for carcinoid heart disease in 12 cases. Gen Thorac Cardiovasc Surg 2011;59: 780-5.

14. Castillo JG, Filsoufi F, Rahmanian PB, Anyanwu A, Zacks JS, Warner RR, et al. Early and late results of valvular surgery for carcinoid heart disease. J Am Coll Cardiol 2008;51:1507-9.

15. McDonald ML, Nagorney DM, Connolly HM, Nishimura RA, Schaff HV. Carcinoid heart disease and carcinoid syndrome: successful surgical treatment. Ann Thorac Surg 1999;67:537-9. 